POLLACK PERIODICA

An International Journal for Engineering and Information Sciences

DOI: $10.1556 / 606.2017 .12 .3 .13$

Vol. 12, No. 3, pp. 141-156 (2017)

www.akademiai.com

\title{
DESCRIPTION OF RAIL TRACK GEOMETRY DETERIORATION PROCESS IN HUNGARIAN RAIL LINES NO. 1 AND NO. 140
}

\author{
Richárd NAGY \\ Department of Transport Infrastructure, Széchenyi István University, Egyetem tér 1 \\ H-9026 Győr, Hungary, e-mail: nagy.richard@sze.hu
}

Received 15 November 2016; accepted 6 June 2017

\begin{abstract}
The aim was the perfection of an analytic examination, which describes the track deterioration process, characterized the correspondences more precisely and better to use in practice. This method was based on the destruction's theory of the railway track geometry and it exploited the possibilities of recent computer technology. More than one million measuring car (FMK-004) data were processed than analyzed and defined by configuring and programming a new method. The results of this method were descriptive functions, which afford interpretable information about the geometrically destruction's occurrences of the different railway lines.
\end{abstract}

Keywords: Rail geometric deterioration, Curve fitting with regression, Track dimensioning factor, Measuring and qualifying numbers, Deterioration time difference fraction, Reserve time, Qualification category

\section{Introduction}

There are two geometrical denominations in connection with rail tracks. The first one is the absolute geometry, which is planned by the rail designing engineer in case of newly-built rails or rail reconstructions with alignment data, cross section data and long section data and realizes based on geodetic alignment [1], [2]. The second denomination is the relative rail geometry, which describes the position of rails to each other and to the basic lines and plane, so it shows the deviation compared to the error-free position [3]-[5]. The deterioration process of relative geometry is affected by several factors, which mostly come from traffic on it and from environmental effects [6]-[11]. The 
deterioration of the track without any regulation works can be described with the following equation:

$$
C=C_{0} \cdot e^{\alpha m v^{2}}
$$

where $C$ is the general characteristic of the geometric condition of the rail; $C_{0}$ is the number describing the initial condition; $\alpha$ is the so-called track dimensioning factor depending on the structural formation; $m$ is the rolling load in tons and $v$ is the equivalent speed.

From a technical point of view this quality deterioration is firstly due to the interaction between the running rail vehicle and the rail track, secondly to the effect of the weather. The condition of the rail track suffers structural deterioration from the implementation time. As a result of the rolling friction the wheels and rails wear away, the tight rail fastenings loosen because of the sinking - rising movements of the track, the sleepers are pushed increasingly into the ballast bed, the rail ballast granules are forced into the protection layer or if there is no one, into the subgrade. In case of superpose of all these effects there will be size differences and later on, location errors evolve in the rail. The relative geometry of the rail track is described with three quantities along with others:

- alignment;

- longitudinal level;

- track twist.

Using the measuring numbers created for these three quantities, the Summary qualifying number weighted with ADded track twist (SAD) qualifying number describes the general geometric condition of the track. It is calculated to a given qualifying length (earlier $500 \mathrm{~m}$, currently $200 \mathrm{~m}$ ), [12].

\section{Critical observations}

Until now in the literature the model was given with the equation (1) created by Dr. Vaszary Pál [13] (Fig. 1). This is a clear model, the process is undisturbed by operational interferences, but differs from reality more and more as it is moved forward along the $\alpha m v^{2}$ axis. The condition of the rail track can not deteriorate forever, some time later the deterioration function has to be tended asymptotically towards a border condition.

In reality the geometric deterioration of the track is not an undisturbed process, because from time to time regulation work has to be performed on the line as a function of the condition (Fig. 2).

In connection with Vaszary's formula, equation (1), it must be stated that the product $\alpha m v^{2}$ is difficult to describe numerically in lack of values of $\alpha$ factor, and the condition of the substructure also plays a huge role in the rail track deterioration process. 


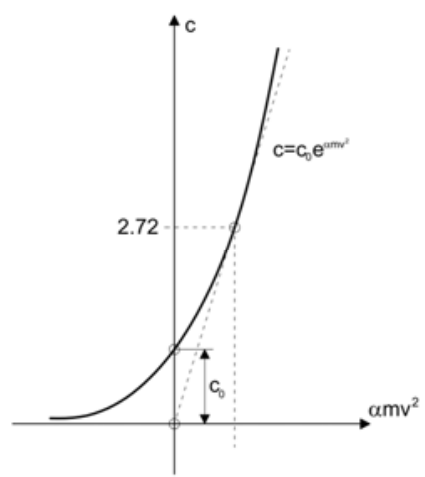

Fig. 1. The equation of the track geometric deterioration according to [6]

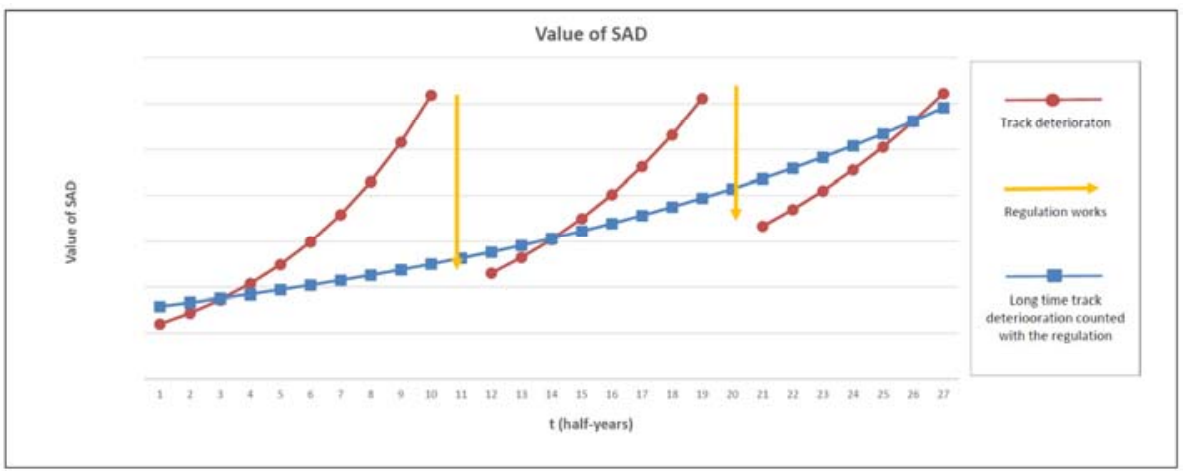

Fig. 2. The effect of the track regulation works on the deterioration process

\section{Creating a new procedure}

The FMK-004 measuring car of Hungarian State Railways Central superstructure Examiner Ltd (MÁV KFV Ltd) provided measuring and qualifying numbers about the railway tracks at a stated frequency from the $2^{\text {nd }}$ half of 1999 until the $2^{\text {nd }}$ half of 2013. In the year 2013 the evaluation system has been changed, so the work with long data series is possible only with values, which were processed by FMK-004 measuring car until this year. Measuring and qualifying numbers are provided for each 500 meter length of the tracks. In the Hungarian railway network there are 16.250 pieces of qualifying sections with 500 meter length and altogether the data of 29 terms are available - counting with 2 measurements a year. That is 471.250 data to each measuring and qualifying number, and altogether (longitudinal level, alignment, twist and SAD) 1.885.000 data, which shows the extensiveness of the examination. After optimizing the data chart and removing the incomplete lines there are 1.072.420 data remained for analysis. 
It can easily be understood that it is an impossible task to analyze this amount of data with manual methods. So a method of progress was created, which correctly and valuably handles and processes this huge amount of data in a controlled way with given initial figures and boundary conditions.

\subsection{The bases of the procedure}

As mentioned earlier, the $\alpha m v^{2}$ product factors cannot be handled by a numerically correct mode in the model, described by equation (1), so the model of the rail geometric deterioration is reformed according to the theory used at the Technical University of Graz [14], [15]:

$$
C_{S A D_{i}}=C_{S A D_{0}} \cdot e^{b t},
$$

where $C$ value is the qualifying number $C=S A D ; C_{0}$ is the value of the qualifying number determined during the first measurement after maintenance.

The $b \cdot t$ should be used instead of the product $\alpha m v^{2}$, where $b$ value is dimensioned factor, which depends on the super-structural parameters (e.g. rail profile, sleepers type and distance, ballast thickness) and the sub-structural parameters (e.g. $E_{2}$ bearing capacity values on protection layer/sub-base) [16]-[18]; $t$ value has elapsed time. (It should be mentioned that the worse the quality of track geometry, the deterioration process is the faster. Due to low financing of maintenance of railway tracks in Hungary all the track faults cannot be eliminated. The extant track faults will be deteriorated forward due to the cancelled (or delayed) maintenance, and other new faults can be evolved. In case the size of the track faults exceed the prescribed value contained the maintenance regulations related to railway tracks speed restrictions have to be used, i.e. a reduced speed is allowed in this section. At the end of this kind of sections additional acceleration energy demand comes forward as compared to state if the train can be driven with constant speed [19]).

\subsection{The course of the procedure}

A large Excel table was created which contains all the measuring and qualifying numbers of each rail line in Hungary recorded with the FMK-004 measuring car from the second half of 1999 to the second half of 2013. The compiled large table was reduced to 1.072 .420 data due to the changes mentioned above, which is the number of data taken into account.

\section{The process of the automatic procedure}

The automatic procedure (program henceforth) makes a catalogue of the lines found in the large table. It collects the initial and the final segments of the given line, the rownumber of the initial and final segment in the large table and provides the number of the 500-meter sections in the given line. From this catalogue the program knows, which fields to read when it analyzes the given rail line. After reading the first line it analyzes 
the data related to the 500-meter sections according to the description in the paragraph beginning with the analysis process of a 500-meter long qualifying section. If the analysis is completed the program goes on to the next 500-meter section.

When the last 500-meter section is analyzed, all the regression equations are completed for the $\mathrm{b}$ dimensioned factor related to all qualifying sections.

The program is able to calculate the curve fitting with regression according to linear, exponential, power or natural based logarithm deterioration.

The program draws the distribution ( $n$ and $m$ ) of the equation parameters according to the type of curve fitting with regression one by one.

The result of linear regression calculation in parametrically:

$$
y_{i}=n_{i} x+m_{i} .
$$

The result of exponential regression calculation parametrically:

$$
y_{i}=m_{i} e^{n_{i} x}
$$

The result of power regression calculation parametrically:

$$
y_{i}=m_{i} x^{n_{i}} .
$$

The result of natural based logarithm calculation parametrically:

$$
y_{i}=n_{i} \ln (x)+m_{i}
$$

Currently the examinations are continuing according to the exponential fitting.

\section{Distribution of the results of exponential regression calculation}

The program calculates the (2)-(5) equations for each 500-meter section of the indicated line and describes them in a frequency histogram, where there are data from at least 7 consecutive terms without track regulation.

In Fig. 3 and Fig. 4 the frequency diagrams of parameters $n$ and $m$ in the exponential deterioration equations of SAD values can be seen. It was measured along the railway line No. 1 , where sections were built with $54 \mathrm{~kg} / \mathrm{m}$ rails.

In Fig. 5 and Fig. 6 there are the frequency diagrams of parameters $n$ and $m$ in the exponential deterioration equations of SAD values measured along the railway line No. 1, where sections were built with $60 \mathrm{~kg} / \mathrm{m}$ rails.

There are differences between the examined sections not only in the rail systems (54E1 and 60E1), but in the sleeper types (LM and LW) and the types of rail fastenings (Skl-1 and Skl-14).

In the functions the value of parameter $n$ is the $b$ dimensioned factor itself, while parameter $m$ shows where the function crosses $y$ axis so that it gives the value of $S A D_{0}$. 
When the function describing the geometric deterioration process of a given railway track is unknown, it is mostly the speed of deterioration depending on the type of the curve fitting with regression is what we look for. The parameter $n$ shows the deterioration speed in linear and non-linear cases as well.

The parameter $m$ also provides interesting information, it shows the condition of the given rail track as a result of the regulation work.

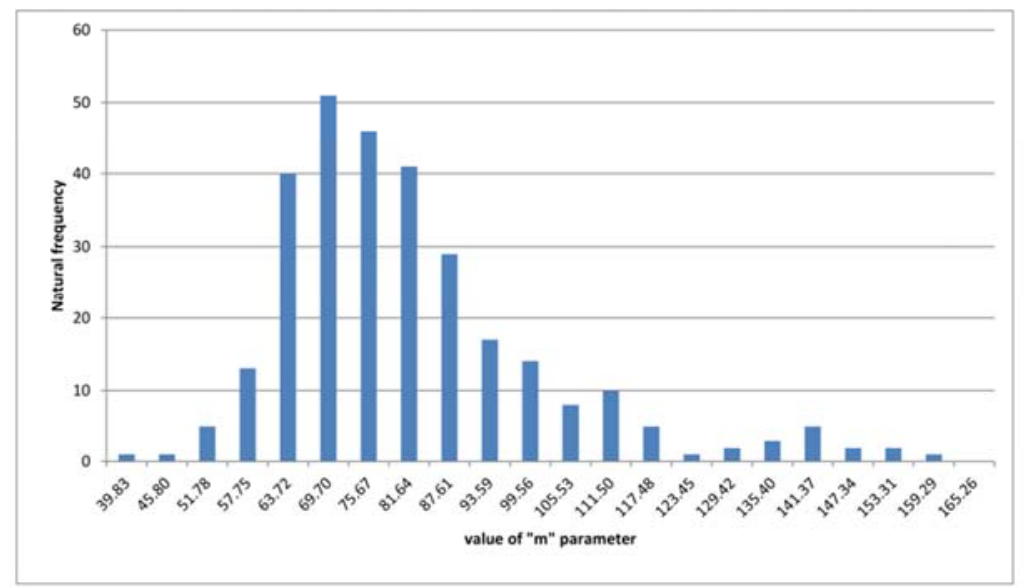

Fig. 3. The natural frequency diagram of parameter $m$ in the exponential deterioration equation for railway line No. 1, where sections were built with $54 \mathrm{~kg} / \mathrm{m}$ rails

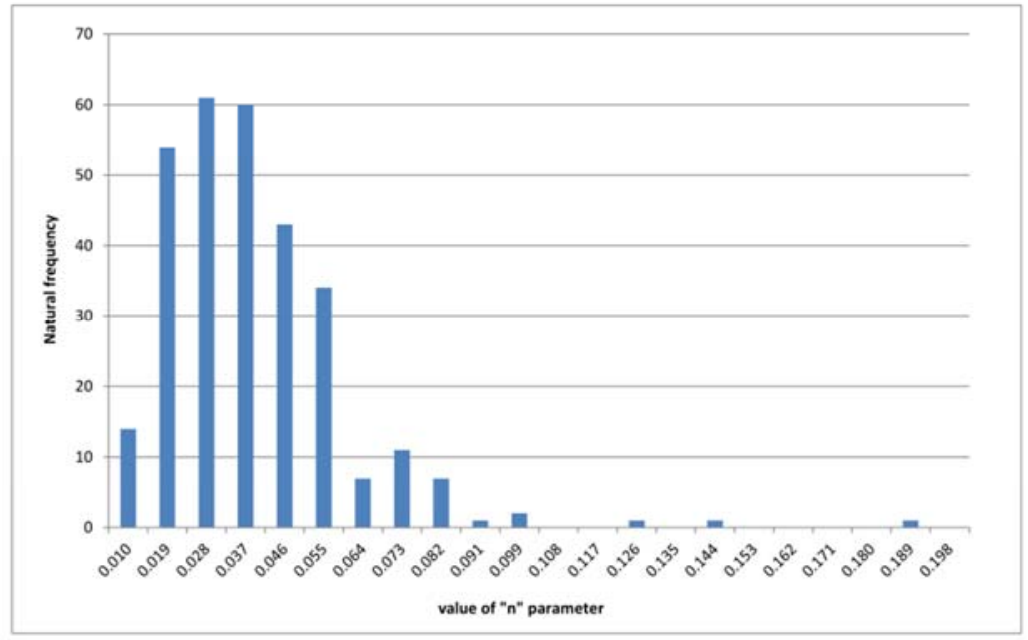

Fig. 4. The natural frequency diagram of parameter $n$ in the exponential deterioration equation for railway line No. 1, where sections were built with $54 \mathrm{~kg} / \mathrm{m}$ rails 


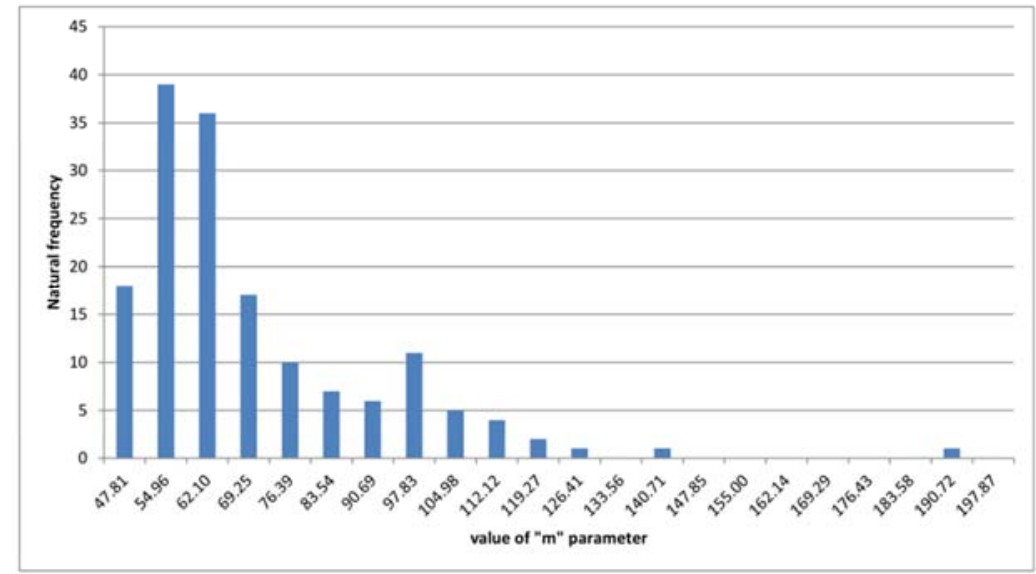

Fig. 5. The natural frequency diagram of parameter $m$ in the exponential deterioration equation for railway line No. 1, where sections were built with $60 \mathrm{~kg} / \mathrm{m}$ rails

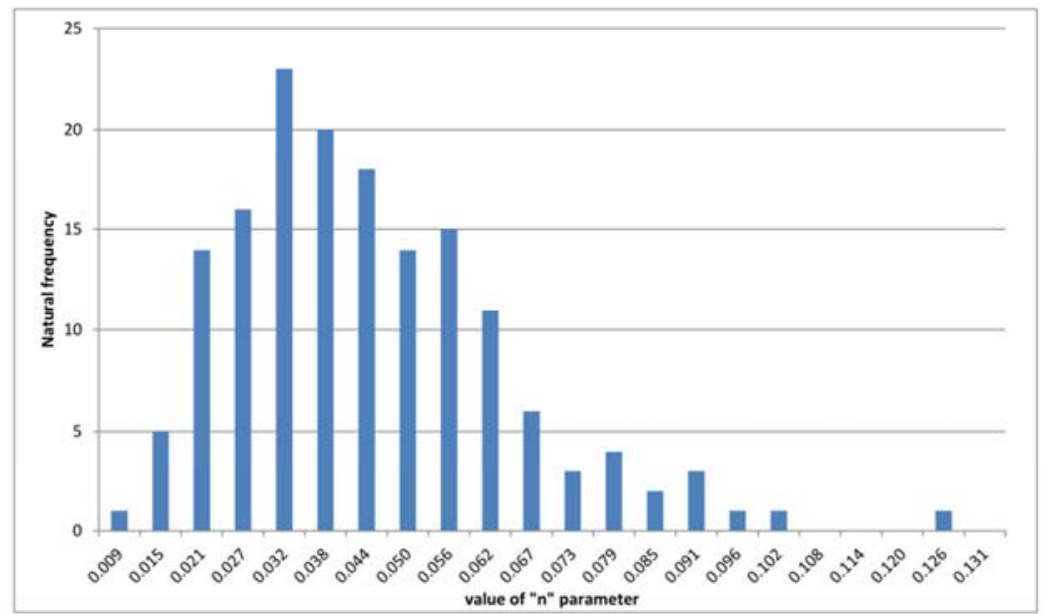

Fig. 6. The natural frequency diagram of parameter in the exponential deterioration equation for railway line No. 1 , where sections were built with $60 \mathrm{~kg} / \mathrm{m}$ rails

After appointing the value set the program draws up the distribution of the given parameter. After this, the mean value of the given parameter weighted with $\mathrm{R}^{2}$ value can be calculated with the narrowed value set.

The program collects the mathematical and graphic results in a separate file, gives a name to the file, deletes the chart and calls in for the data of the following line with the help of a catalogue and the analysis starts again.

To continue the evaluation, the values belonging to $n$ parameter are selected, which are used by the program to calculate a more exact result. 


\section{The analysis process of a 500-meter long qualifying section}

The process starts with the program looking for consecutive terms without regulation work in the given 500-meter section. It can be determined separately how many consecutive operation-free terms should be the minimum that the program takes into account during the analysis. The program indexes each inspected datum related to the term with 0 where there is a condition improvement (characterized by SAD value) higher than $5 \%$ compared to the previous term. This value indexed with 0 will be the $S A D_{0}$ value during the analysis when the examination of the qualifying number is described.

Transforming the formula above (2) the $b$ sub- and super-structural dimensioned factors are received as

$$
b=\frac{\ln \left(C_{S A D_{i}} / C_{S A D_{0}}\right)}{t} .
$$

Based on the SAD numbers the program determines the equation of the given data series and the determination coefficient describing the rate of the fitting by the setting of linear (2) and non-linear (3), (4), (5) regression functions.

Hereinafter only the regression equations having a determination coefficient of

$$
R^{2}=0.75
$$

or higher will be taken into consideration.

As the program completes the analysis of a 500-meter section, it continues with the next 500-meter rail section.

When the last 500-meter track section has been already analyzed and the analysis has been completed according to the scheme in Fig. 7, the program goes on to the next line.

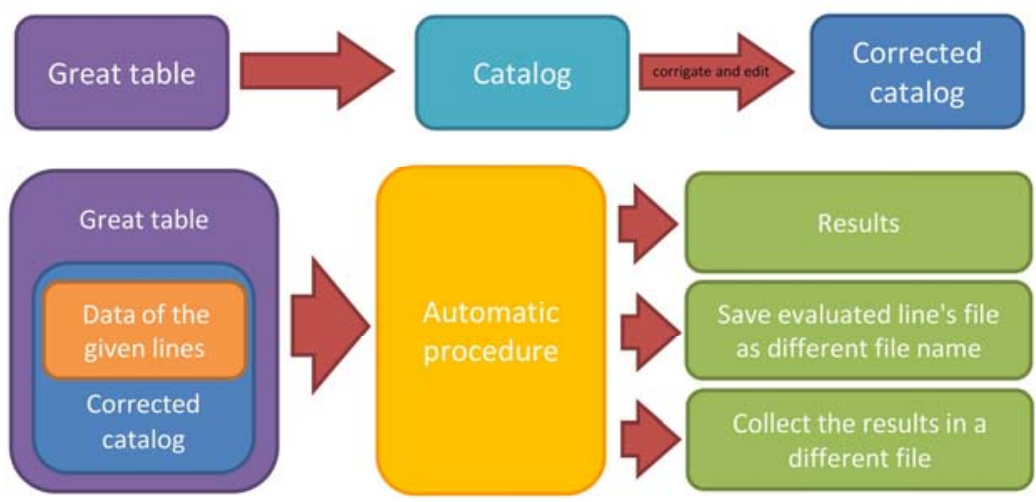

Fig. 7. The automatization figure of the program 


\section{Assigning other parameters}

The procedure described above determines the deterioration equation of the given line on the basis of the unfiltered data.

It is a fact that a lot of parameters are available for the examined lines, including horizontal geometry, speed, the track system, the rail system, the type of sleeper, the sleeper spacing and the ballast thickness, etc. Despite this, there are factors in the analysis that the program cannot take into account.

The parameters mentioned above must be assigned to the 500-meter rail sections of the lines examined, which required separate programming and procedure creation over again. The following Table I provides the information for railway line No. 1 about the diversity of rail system, currently it would be 70 rows. It can be simplified with creating a separate program.

Table I

Sections of rail systems

\begin{tabular}{|c|c|c|c|c|}
\hline Zone & $\begin{array}{c}\text { Initial } \\
\text { section }\end{array}$ & Zone & $\begin{array}{c}\text { Final } \\
\text { section }\end{array}$ & Rail system \\
\hline 1 & 0 & 1 & 1340 & MÁV48,5 \\
\hline 1 & 1340 & 1 & 11800 & $54 \mathrm{E} 1$ \\
\hline 1 & 11800 & 1 & 12300 & $60 \mathrm{E} 1$ \\
\hline 1 & 12300 & 1 & 17299 & $54 \mathrm{E} 1$ \\
\hline 1 & 17299 & 1 & 17600 & $60 \mathrm{E} 1$ \\
\hline$\ldots$ & $\ldots$ & $\ldots$ & $\ldots$ & $\ldots$ \\
\hline 3 & 188370 & 3 & 188495 & $60 \mathrm{E} 1$ \\
\hline 3 & 188495 & 3 & 189115 & $54 \mathrm{E} 1$ \\
\hline 3 & 189115 & 3 & 189476 & $60 \mathrm{E} 1$ \\
\hline 3 & 189476 & 3 & 192720 & $54 \mathrm{E} 1$ \\
\hline
\end{tabular}

If this assignment has been completed, it is possible to call the 500-meter long railway track sections that should be evaluated into the program according to the filtered parameters.

In the following part of the article the analysis of the data of railway line No. 1 (Budapest - Hegyeshalom - Rajka) and line No. 140 (Cegléd - Szeged) will be published. The two lines have 500-meter rail sections that have identical and different technical characteristics from a super-structural point of view. At the same time, there is a significant difference between the numbers of trains passing through the two lines.

\section{Results and deductions}

\subsection{Determining $S A D(t)$ deterioration functions}

In Table II there are exponential equations $\operatorname{SAD}(t)$, where $t$ means the number of elapsed terms (half a year) since the last maintenance. The equations in Table II characterize the deterioration of the geometrical condition on track sections of line 
No. 1 and No. 140 built up with system 48, 54 and 60 superstructures what is shown in Fig. 8 and Fig. 9.

\section{Table II}

SAD $(t)$ deterioration functions

\begin{tabular}{|c|c|c|c|c|}
\hline Line & Rail system & Equation & $\mathrm{SAD}_{0}$ & $\mathrm{~b}$ \\
\hline \multirow{2}{*}{1.} & $54 \mathrm{E} 1$ & $\mathrm{SAD}_{54}=85.84569 * \exp (0.03897 * \mathrm{t})$ & 85.84569 & 0.03897 \\
& $60 \mathrm{E} 1$ & $\mathrm{SAD}_{60}=75.28696 * \exp (0.03788 * \mathrm{t})$ & 75.28696 & 0.03788 \\
140. & $\mathrm{MÁV} 48.5$ & $\mathrm{SAD}_{48,5}=112.511 * \exp (0.05913 * \mathrm{t})$ & 112.511 & 0.05913 \\
& $60 \mathrm{E} 1$ & $\mathrm{SAD}_{60}=83.2813 * \exp (0.04184 * \mathrm{t})$ & 83.2813 & 0.04184 \\
\hline
\end{tabular}

Based on the result above the deterioration condition of a track built with a given rail system can be estimated as a function of the terms, if there is no regulation work in the future as well.

\subsection{Determination of deterioration time difference function}

Furthermore, with the knowledge of the current $S A D_{54}$ qualifying number it can be determined what $S A D_{60}$ values would have evolved if they would have been built with superstructure system 60 ,

$$
\begin{aligned}
& S A D_{54}^{t}=S A D_{54}^{0} \cdot e^{b_{54} t}, \\
& S A D_{60}^{t}=S A D_{60}^{0} \cdot e^{b_{60} t},
\end{aligned}
$$

where $t$ is the number of elapsed terms since the last maintenance; $b^{54}$ and $b^{60}$ are the track dimensioned factors with a given superstructure; $S A D_{54}{ }^{t}, S A D_{60}{ }^{t}$ are the values of $\mathrm{SAD}$ measured in the $t^{\text {th }}$ term after maintenance of the rail line with superstructure systems 54 and 60.

From formula (9) the value of $t$ is received

$$
t=\frac{\ln \left(S A D_{54}^{t} / S A D_{54}^{0}\right)}{b_{54}}
$$

then inserted $t$ into formula (10) it results in

$$
S A D_{60}^{t}=S A D_{60}^{0} \cdot e^{b_{60} \frac{\ln \left(S A D_{54}^{t} / S A D_{54}^{0}\right)}{b_{54}}},
$$


so $S A D_{60}{ }^{t}$ shows what value SAD would take in $t$ number of elapsed terms after the last maintenance if there were system 60 superstructure instead of system 54 superstructure on the given line. It has to note that the SAD means not only the quality of the superstructure, but also the ballast and substructure. The tracks assembled with $60 \mathrm{~kg} / \mathrm{m}$ rails are consequently newer, the ballast and substructure have higher quality.

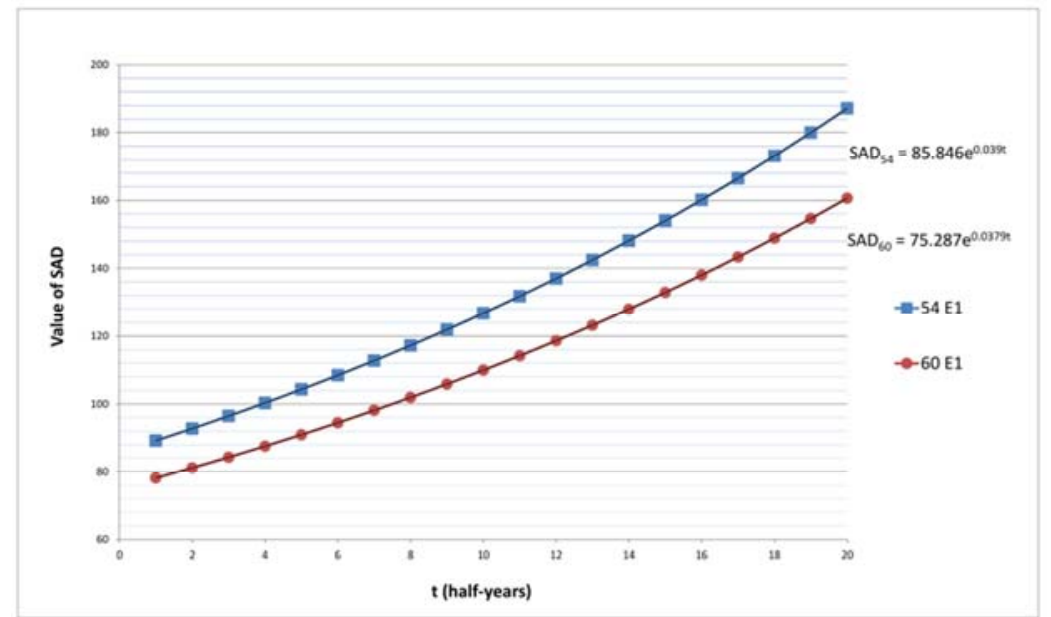

Fig. 8. Exponential deterioration of track geometry on railway line No. 1, as a function of the number of terms

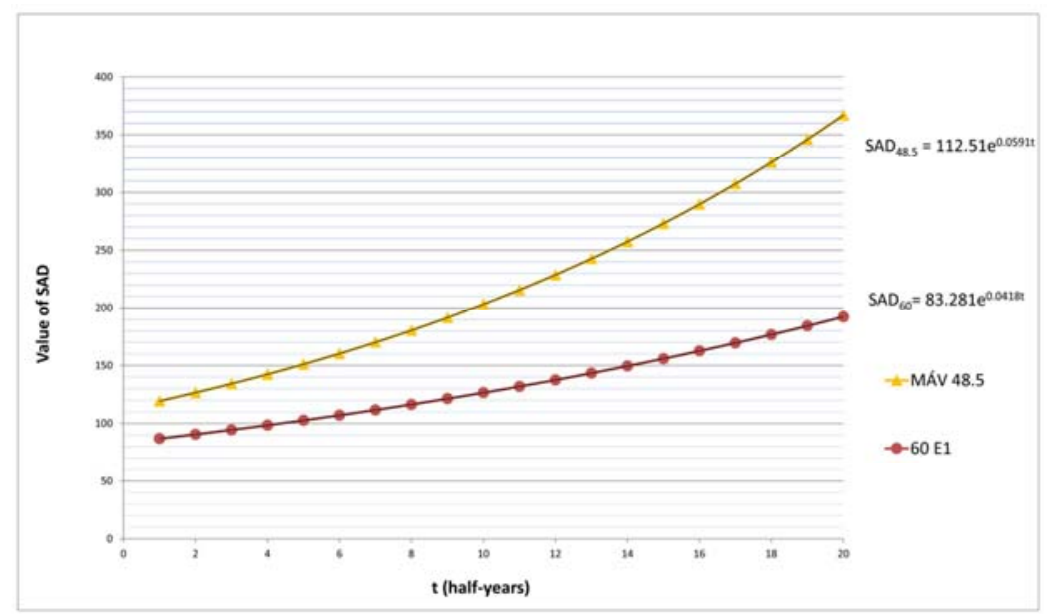

Fig. 9. Exponential deterioration of track geometry on railway line No. 140, as a function of the number of terms 
So, if the sections of an existing line with the same superstructure, which is system 54 in this case were rebuilt with system 60 superstructure, it can be calculated how much more economical the operation would be due to the lack of regulation interventions if the number of interventions are only considered supposing the same interventional efficiency.

Table I shows the systematic diversity of superstructure on line No. 1.

The question is given if a line was built with system 54 and 60 superstructures in turns, how much is the deterioration time difference between the two systems.

Calculating formula (11) and formula (13)

$$
t=\frac{\ln \left(S A D_{60}^{t} / S A D_{60}^{0}\right)}{b_{60}}
$$

for the two examined lines the results are linear functions as it can be seen in Table III.

\section{Table III}

Deterioration time difference functions

\begin{tabular}{|c|c|c|c|}
\hline Line & Function & Steepness & $\mathrm{t}_{0}$ \\
\hline 1 & $t_{i k}=0.0288 t+3.4647$ & 0.0288 & 3.4647 \\
140 & $t_{i k}=0.4132 t+7.1899$ & 0.4132 & 7.1899 \\
\hline
\end{tabular}

In the function describing the deterioration time difference $t_{0}$ shows how many terms of time difference there are between the bigger and the smaller weighed rail systems on the given line after the moment of maintenance. So on line No. 1 the line sections constructed with 60 track system almost has a deterioration time difference of 3.5 terms compared to structure system 54 and on line $\mathrm{Nr}$. 140 the reserve is at least 7 terms compared to system 48 superstructure.

The equations in Table III also show that how many $t_{i k}$ terms will be elapsed until the sections with track system 60 will be in the same condition than the sections with track system 54 in the actual half-year.

In Fig. 10 it can be seen clearly that in case of line No. 140 has a much bigger deterioration time difference than in case of line No. 1.

\subsection{The determination of reserve time}

The qualifying categories for continous welded rail tracks (500-metre qualifying length, $v=160 \mathrm{~km} / \mathrm{h}$ track speed) according to regulation D. 54 chapter 51 . [20] are the following (Table IV).

In Table $V$ there are exponential equations of the geometric deterioration of track sections separated according to track systems (54 and 60) and track geometry on line No. 1. 


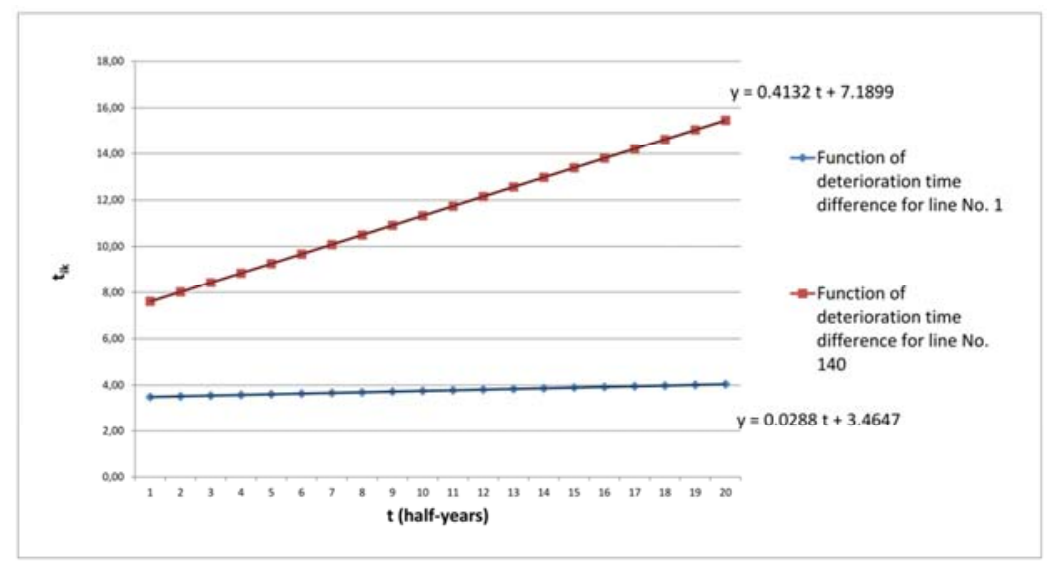

Fig. 10. Functions of deterioration time difference for line No. 1 and No. 140

Table IV

Qulifying categories limits

\begin{tabular}{|c|c|c|c|c|c|c|}
\hline Speed & Q1 & Q2 & Q3 & Q4 & Q5 & Q6 \\
\hline $160 \mathrm{~km} / \mathrm{h}$ & 67.3 & 75.9 & 86.8 & 105.4 & 118.6 & 148.4 \\
\hline
\end{tabular}

Table V

$\mathrm{SAD}(\mathrm{t})$ Deterioration functions on line No. 1

\begin{tabular}{|c|c|c|c|c|}
\hline $\begin{array}{c}\text { Rail } \\
\text { system }\end{array}$ & Geometry & Function & $\mathrm{SAD}_{0}$ & $\mathrm{~b}$ \\
\hline \multirow{2}{*}{54} & straight & $\mathrm{SAD}^{54 \mathrm{~s}}=81.89145 * \exp (0.03888 * \mathrm{t})$ & 81.89145 & 0.03888 \\
& curved & $\mathrm{SAD}^{54 \mathrm{c}}=83.6356 * \exp (0.04893 * \mathrm{t})$ & 83.6356 & 0.04893 \\
& straight & $\mathrm{SAD}^{60 \mathrm{~s}}=68.21551 * \exp (0.03498 * \mathrm{t})$ & 68.21551 & 0.03498 \\
& curved & $\mathrm{SAD}^{60 \mathrm{c}}=79.88571 * \exp (0.03709 * \mathrm{t})$ & 79.88571 & 0.03709 \\
\hline
\end{tabular}

Fig. 11 and Fig. 12 were created with the use of $S A D(t)$ deterioration functions according to Table VI and regulation D. 54, chapter 51 [3]. Both of them can describe well the change of the $S A D(t)$ deterioration function. After the last intervention the time period that reaches the limit of the given qualifying category is called the reserve time belonging to the given qualifying category $\left(t_{01}, t_{02} \ldots\right)$.

By transforming the formula (11) the reserve time can be calculated with the following formula:

$$
{ }^{t} Q_{i}=\frac{\ln \left(Q_{i} / S A D_{j}^{0}\right)}{b_{j}}
$$

where $Q_{i}$ is the $\mathrm{SAD}$ value of the given qualifying category; $i=1, \ldots, 6$ is the given qualifying categories; $j$ is the system of the superstructures, number 54, 60 . 


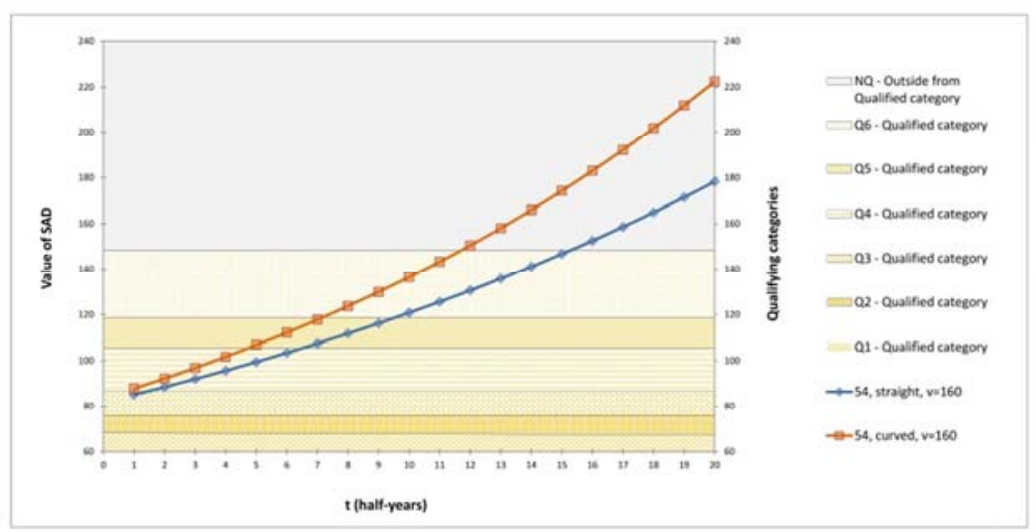

Fig. 11. Comparison of SAD values of straight and curved track sections built with $54 \mathrm{~kg} / \mathrm{m}$ rails on line No. 1 to the qualifying categories

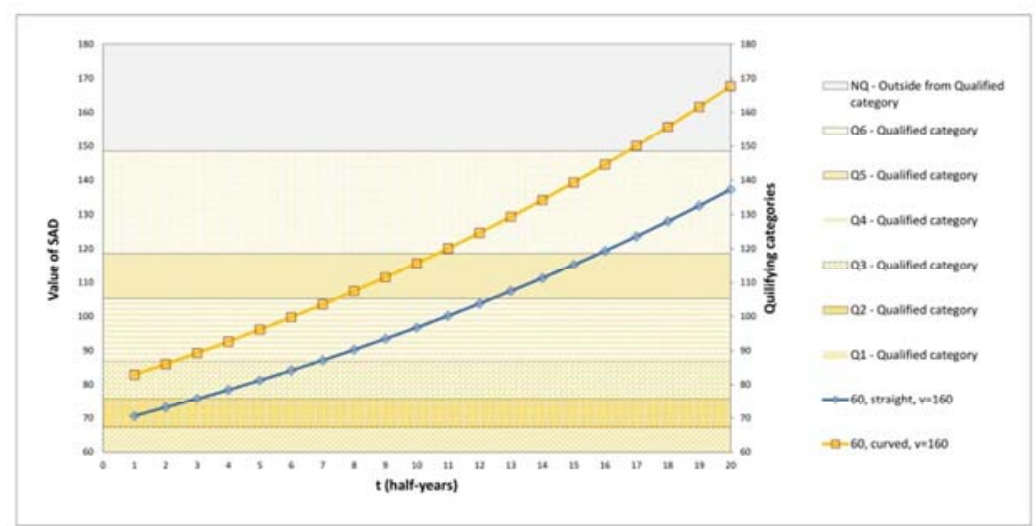

Fig. 12. Comparison of SAD values of straight and curved track sections built with $60 \mathrm{~kg} / \mathrm{m}$ rails on line No. 1 to the qualifying categories

The reserve times belonging to the different track systems and qualifying categories on line No. 1 are in Table VI and Table VII.

\section{Table VI}

Reserve times for track system 54

\begin{tabular}{|c|c|c|c|c|c|c|}
\hline & $\begin{array}{c}\mathrm{t}_{\mathrm{M} 1} \\
\text { (half- } \\
\text { year) }\end{array}$ & $\begin{array}{c}\mathrm{t}_{\mathrm{M} 2} \\
\text { (half- } \\
\text { year) }\end{array}$ & $\begin{array}{c}\mathrm{t}_{\mathrm{M} 3} \\
\text { (half- } \\
\text { year) }\end{array}$ & $\begin{array}{c}\mathrm{t}_{\mathrm{M} 4} \\
\text { (half- } \\
\text { year) }\end{array}$ & $\begin{array}{c}\mathrm{t}_{\mathrm{M} 5} \\
\text { (half- } \\
\text { year) }\end{array}$ & $\begin{array}{c}\mathrm{t}_{\mathrm{M} 6} \\
\text { (half- } \\
\text { year) }\end{array}$ \\
\hline $\begin{array}{c}\text { 54 s. superstructure, } \\
\text { straight }\end{array}$ & - & - & 1.49 & 6.49 & 9.52 & 15.29 \\
$\begin{array}{c}54 \text { s. superstructure, } \\
\text { curved }\end{array}$ & - & - & 0.76 & 4.73 & 7.14 & 11.72 \\
\hline
\end{tabular}

Pollack Periodica 12, 2017, 3 
Table VII

Reserve times for track system 60

\begin{tabular}{|c|c|c|c|c|c|c|}
\hline & $\begin{array}{c}\mathrm{t}_{\mathrm{M} 1} \\
\text { (half- } \\
\text { year) }\end{array}$ & $\begin{array}{c}\mathrm{t}_{\mathrm{M} 2} \\
(\text { half- } \\
\text { year) }\end{array}$ & $\begin{array}{c}\mathrm{t}_{\mathrm{M} 3} \\
\text { (half- } \\
\text { year) }\end{array}$ & $\begin{array}{c}\mathrm{t}_{\mathrm{M} 4} \\
\text { (half- } \\
\text { year) }\end{array}$ & $\begin{array}{c}\mathrm{t}_{\mathrm{M} 5} \\
\text { (half- } \\
\text { year) }\end{array}$ & $\begin{array}{c}\mathrm{t}_{\mathrm{M} 6} \\
\text { (half- } \\
\text { year) }\end{array}$ \\
\hline $\begin{array}{c}60 \text { s. superstructure, } \\
\text { straight }\end{array}$ & - & 3.05 & 6.89 & 12.44 & 15.81 & 22.22 \\
$\begin{array}{c}60 \text { s. superstructure, } \\
\text { curved }\end{array}$ & - & - & 2.24 & 7.47 & 10.65 & 16.70 \\
\hline
\end{tabular}

\section{Conclusion}

The advantage of the reviewed procedure is that the measuring dates of the superstructure measuring car, which were used mostly for state definition, can be usable more widely hereafter. On the one hand by analyzing the deterioration processes the date of the required intervention (practices or restriction) became plan-able in an exact way. On the other hand it supports the creating of economical calculations, which is significant when decisions are taken between investment and maintenance. The reviewed procedure calculates this progress automatically with the modern computing devices.

\section{References}

[1] Fischer Sz. Comparison of railway track transition curves, Pollack Periodica, Vol. 4, No. 3, 2009, pp. 99-110.

[2] Horvát F. The railway geometry progress from the beginning to nowadays (in Hungarian) Indóház, Vasúti Magazin, Vol. 9, No. 4, 2013, pp. 2-7.

[3] Fischer Sz., Horvát F. Superstructure Stabilization of Ballast Bedded Railway Tracks with Geogrids, Hungarian Journal of Industrial Chemistry, Vol. 39, No. 1, 2011, pp. 101-106.

[4] Šestáková J., Mečár M. Evaluation of track design and track geometry of the track with unconventional structure of railway superstructure, Procedia Engineering, Vol. 111, 2015, pp. 709-716.

[5] Lestoille N., Soize C., Funfschilling C. Stochastic prediction of high-speed train dynamics to long-term evolution of track irregularities, Mechanics Research Communications, Vol. 75, 2016, pp. 29-39.

[6] Vinkó Á. Monitoring and condition assessment of tramway track using in-service vehicle, Pollack Periodica, Vo. 11, No. 3, 2016, pp. 73-82.

[7] Papp H., Liegner N._Investigation of internal forces in the rail due to the interaction of CWR tracks and steel railway bridges with ballasted track superstructure, Pollack Periodica, Vol. 11, No. 2, 2016, pp. 65-74.

[8] Cárdenas-Galloa I., Sarmientoa C. A., Moralesa G. A., Bolivara M. A., AkhavanTabatabaeia R. An ensemble classifier to predict track geometry degradation, Reliability Engineering \& System Safety, Vol. 161, 2017, pp. 53-60.

[9] Andradea A. R., Teixeirab P. F. Statistical modeling of railway track geometry degradation using Hierarchical Bayesian models, Reliability Engineering \& System Safety, Vol. 142, 2015, pp. 169-183. 
[10] Lestoille N., Soize C., Funfschilling C. Stochastic prediction of high-speed train dynamics to long-term evolution of track irregularities, Mechanics Research Communications, Vol. 75, 2016, pp. 29-39.

[11] Lee J. S., Choi I. Y., Kim S. H., Moon D. S. Kinematic modeling of a track geometry using an unscented Kalman filter, Measurement, Vol. 94, 2016, pp. 707-716.

[12] MSZ EN 13848-6:2014.

[13] Vaszary P. The theory of the track degradation, in I. Mezei and F. Horváth (Eds.) Railway construction and maintenance, Part II., Magyar Államvasutak Ltd. Budapest, 1999.

[14] Veit P. Rail steel grades in track, Europien Railway Preview, Vol. 19, No. 4, 2013, pp. 32-36.

[15] Veit P. The sustainability of railways (in Hungarian), Sinek Világa, No. 2, 2015, pp. 2-7.

[16] Fischer Sz. Investigation of inner shear resistance of geogrids built under granular protection layers and railway ballast, Nauka ta Progres Transportu, Vol. 59, No. 5, 2015, pp. 97-106.

[17] Fischer Sz., Szatmári T. Investigation of the geogrid-granular soil combination layer with laboratory multi-level shear box test, 6th European Geosynthetics Congress, Eurogeo6, Ljubljana, Slovenia, 25-28 September 2016, pp. 439-448.

[18] Esveld C. Modern railway track, Second Edition, MRT-Productions, Zaltbommel, Netherlands, 2001.

[19] Fischer Sz. Traction Energy Consumption of Electric Locomotives and Electric Multiple Units at Speed Restrictions, Acta Technica Jaurinensis, Vol. 8, No. 3, 2015, pp. 240-256.

[20] D. 54. sz. Build and maintenance specifications and regulations, (in Hungarian), Part I, KÖZDOK, Budapest, 1987. 